Provided for non-commercial research and education use. Not for reproduction, distribution or commercial use.

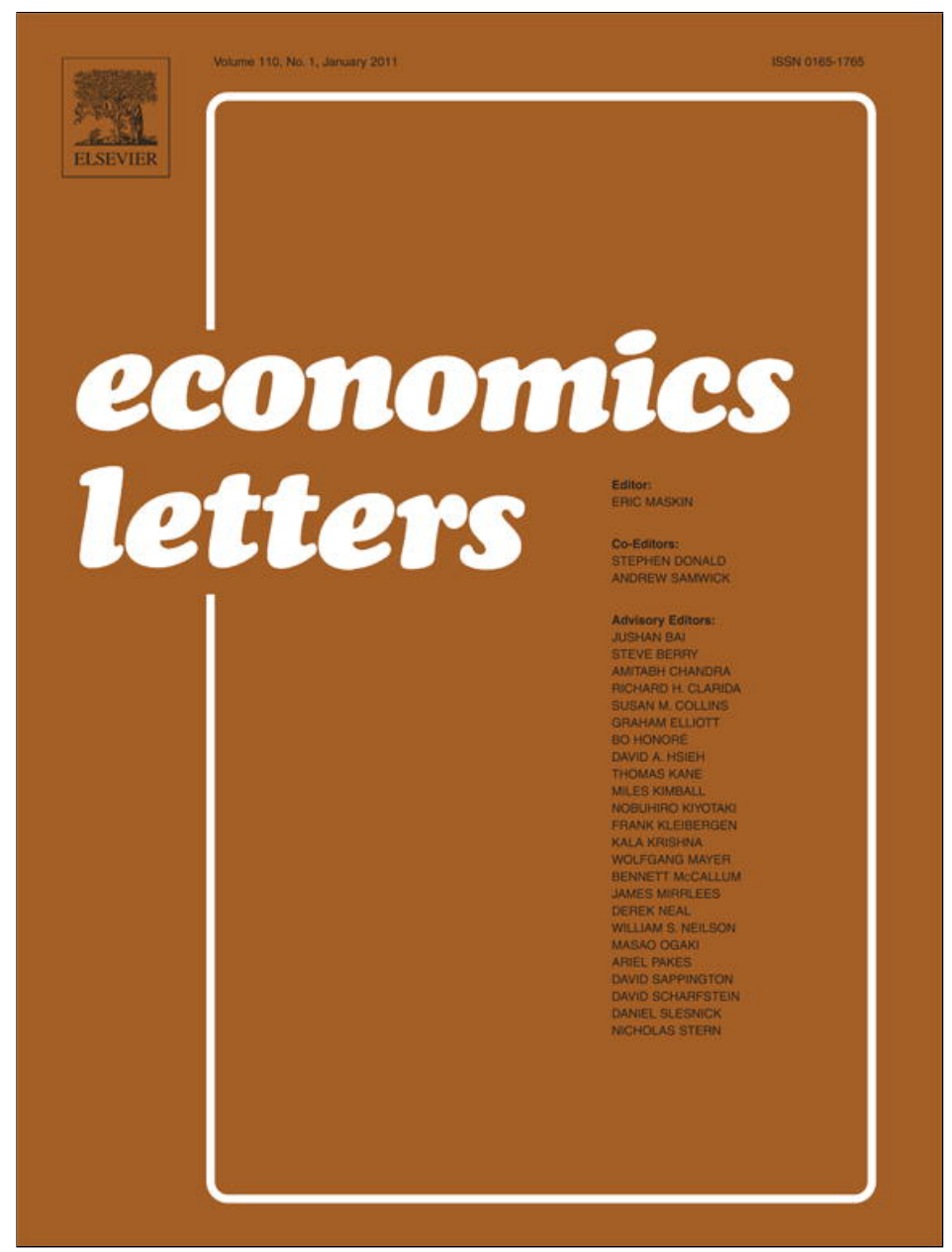

(This is a sample cover image for this issue. The actual cover is not yet available at this time.)

This article appeared in a journal published by Elsevier. The attached copy is furnished to the author for internal non-commercial research and education use, including for instruction at the authors institution and sharing with colleagues.

Other uses, including reproduction and distribution, or selling or licensing copies, or posting to personal, institutional or third party websites are prohibited.

In most cases authors are permitted to post their version of the article (e.g. in Word or Tex form) to their personal website or institutional repository. Authors requiring further information regarding Elsevier's archiving and manuscript policies are encouraged to visit:

http://www.elsevier.com/copyright 


\title{
Charities and the political support for estate taxation ${ }^{\star}$
}

\author{
Georges Casamatta ${ }^{\mathrm{a}}$, Helmuth Cremer $^{\mathrm{b}}$, Pierre Pestieau ${ }^{\mathrm{c}, *}$ \\ ${ }^{\text {a }}$ Toulouse School of Economics (GREMAQ and CNRS), France \\ ${ }^{\mathrm{b}}$ Toulouse School of Economics (IDEI, GREMAQ and IUF), France

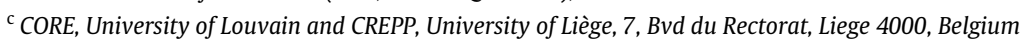

\section{A R T I C L E I N F O}

\section{Article history:}

Received 23 July 2011

Received in revised form

20 December 2011

Accepted 20 December 2011

Available online 30 December 2011

\section{JEL classification:}

$\mathrm{H} 20$

Keywords:

Estate taxation

Charities

Nash equilibrium

\begin{abstract}
A B S T R A C T
We explain why wealthy people often favor estate taxation, while wealthless people oppose it. Wealthy people devote part of their estate to charities. Estate taxation with tax breaks for charities increases contributions to an otherwise underprovided public good.
\end{abstract}

(C) 2011 Elsevier B.V. All rights reserved.

\section{Introduction}

The US is regularly experiencing a lively debate on whether estate tax is good for the economy or not. This debate has been revived recently by the implication of the Economic Growth and Tax Relief Reconciliation Act of 2001 that resulted in a unique situation: there was no estate tax for the year 2010. The proponents of estate tax believe that estate tax essentially prevents the formation of a royalty, while also helping to bridge the disparities in wealth. Supporters of estate tax include billionaires like Warren Buffet and Bill Gates who, along with 2000 wealthy Americans, have signed up for Responsible Wealth, a project of United for a Fair Economy (2011) to advocate reinstating the estate tax in $2011 .{ }^{1}$ Opponents of the estate tax call it death tax because they feel that the government is in effect penalizing death. ${ }^{2}$ They argue that

\footnotetext{
Financial support from the Chair "Marche des risques et creation de valeur" of the FdR/SCOR is gratefully acknowledged.

* Corresponding author. Tel.: +32 4 3663109; fax: +32 43662981.

E-mail address: p.pestieau@ulg.ac.be (P. Pestieau).

1 Responsible Wealth, a project of United for a Fair Economy (2011), is a network of over 700 business leaders and wealthy individuals in the top $5 \%$ of income and/or wealth in the US who use their surprising voice to advocate fair taxes and corporate accountability.

2 For a survey of the arguments pro and con estate taxation, see Cremer and Pestieau (2011).
}

estate tax is double taxation since the wealth was already taxed during its creation as income tax or some other tax. Among the opponents one finds a lot of people who cannot be hurt by estate taxation: they will not pay it like a huge majority of Americans and thus they can only benefit from its proceeds. ${ }^{3}$ To sum up, this highly stylized view suggests that very rich individuals often support bequest taxation while middle class and poor individuals oppose it (even though they - or their heirs - may effectively pay no or very little tax on bequests).

This note provides a possible explanation for such a paradoxical situation. This explanation is based on the taste of wealthy individuals for contributing to a wide array of charities that benefit from tax breaks. Given the public good nature of charities their supply through contributions is known to be suboptimal. ${ }^{4}$ Thus tax breaks, by fostering contributions, can have social benefits that exceed their fiscal cost. As for the wealthless individuals they are less attracted by charitable donations; hence, whether or not they support estate taxation will depend on its redistributiveness. If the tax obeys the benefit tax principle (i.e., equivalence between contributions and benefits), they will be at best indifferent.

\footnotetext{
3 Prabhakar (unpublished) discusses the various reasons why the "death tax" gets so little political support.

4 A survey on charities is provided by Andreoni (2006). On the issue if private provision of public goods, see Bergstrom et al. (1986) and Andreoni (1988).
} 
To make our point we use a simple model with two homogenous groups of individuals. In the first, individuals have an initial endowment that they allocate between a composite good, donation to a charity and bequests. In the second, individuals have a lower endowment that is allocated between the composite good and bequests. Taxing bequests amounts to subsidizing both the composite good and charitable contributions. Such a tax thus fosters contributions (which are otherwise too low in the Nash equilibrium). When the tax proceeds are returned to those who pay the tax, one can expect Group 1 to benefit from the tax and Group 2 to be penalized by it. However, when tax proceeds are used to finance a transfer towards Group 2, that group no longer necessarily looses. As a matter of fact, we will show that depending on the parameters of the model it may (or may not) be possible to design a transfer scheme that would make everyone better off than in the absence of estate taxation.

It is clear that this model could be generalized to reflect real life complexities. Our objective is rather modest. We want to show why wealthy contributors can be in favor of a tax which a priori is supposed to burden them and why it is possible to have a unanimity of individuals in favor of the estate tax.

The rest of the letter is organized as follows. We first look at these two groups as if they were autarkic. And then we look at the overall tax problem.

\section{Group 1: the contributors}

Each member of the first group, that of contributors, has an income $y$ and a utility $U(x, b, G)$ where $x$ is a composite good, $b$ is bequest and $G$ is a charity (a pure public good). The size of this group is $n$. The utility of a contributor is given by

$U(x, b, G)=G+u(x)+u(b)$.

The quasi-linear utility is adopted to make our point in the simplest possible way. It implies no income effect on the demand for either $x$ or $b$. We now consider different types of solution assuming for the time being that the entire population belongs to Group 1 .

\subsection{First-best}

Assuming that equal individuals are treated identically, we define the first-best as the feasible allocation that maximizes the utility of a representative individual. The Lagrangian expression associated with this problem is given by

$\mathcal{L}_{1}=G+u(x)+u(b)-\mu(G / n+x+b-y)$,

where $\mu$ is the multiplier of the resource constraint. Recall that $G$ is a public and, hence, nonrival good. Differentiating with respect to $G, x$ and $b$ and rearranging yields the following first-order conditions (hereafter FOC):

$u^{\prime}(x)=u^{\prime}(b)=n=\mu$.

When $u(\cdot)=\ln (\cdot)$, Eq. (2) simplifies to $x=b=1 / n$. Combining this condition with the resource constraint yields $G=n y-2$.

\subsection{Laissez-faire}

Each individual chooses the contribution $g \geq 0$ and the bequest $b$ that maximize utility given by

$G_{-1}+y-b-x+u(x)+u(b)$,

where $G_{-1}$ denotes the sum of the contributions of the $n-1$ other individuals. In other words, we determine the symmetric Nash equilibrium of the public good contribution game. This yields the FOC

$u^{\prime}(x)=u^{\prime}(b)=1$.

With $u(\cdot)=\ln (\cdot)$, we have $x=b=1$. Hence, $G=$ ny $2 n .^{5}$ Because charity is a public good, the Nash equilibrium level of provision is too low. The difference between equilibrium and optimal level increases with the size of Group 1.

\subsection{Constrained first-best $(x=1)$ and its decentralization as second- best}

We now consider a constrained first-best, where $x$ takes its laissez-faire value. This allocation is a relevant benchmark because we assume that there is no tax (or subsidy) on $x$. With quasi-linear preferences the level of $x$ will then remain at $x=\bar{x}=1$, even when there are taxes on the other goods and/or lump sum transfers (there is no income effect).

The problem is now to choose $g$ and $b$ that maximize

$G+u(\bar{x})+u(b)-\mu(G / n+\bar{x}+b-y)$.

The FOC leads to:

$u^{\prime}(b)=n$.

With the log example: $b=1 / n$ and $G=n y-1-n$.

The above constrained first-best can be achieved with the use of a tax on bequests, $\sigma$, and a lump-sum transfer $T$. Faced with such instruments, Group 1 members solve

$\max _{x, b} G_{-1}+y-b(1+\sigma)-x+T+u(x)+u(b)$,

leading to the FOC

$-(1+\sigma)+u^{\prime}(b)=0$.

With the log example it is sufficient to set $\sigma=n-1$ and $T=$ $\sigma b=(n-1) / n$ to achieve the second-best optimum (recall that $b=1 / n)$.

\subsection{Utility gain}

Let us now measure the maximum utility gain one obtains from moving from the laissez-faire to this second-best. We have

$U^{\mathrm{LF}}=n y-2 n+2 \ln 1$,

$U^{\mathrm{SB}}=n y-1-n+\ln 1-\ln n$,

so that

$\Delta \equiv U^{\mathrm{SB}}-U^{\mathrm{LF}}=n-1-\ln n$.

Observe that $\Delta>0$ as long as $n>1$. It thus appears from this example that a tax on bequests is welfare improving for Group 1. This is because it induces each individual to contribute more to the public good. Recall that the contribution equilibrium implies a level of public good that is too low. Further observe that the (per capita) welfare gain increases in the group size:

$\frac{\partial \Delta}{\partial n}=1-\frac{1}{n}>0$ for $n>1$.

This does not come as a surprise, as we have shown in Section 2.2 that the inefficiency of the public good provision (the difference between optimal and equilibrium level) increases with the group size.

\section{Group 2}

In the second group, which is of size $m$, each individual has an income $w$ and a utility.

$U_{2}(x, b)=u(x)+\beta u(b)$.

\footnotetext{
5 The income level $y$ is assumed to be larger than 2, in order to have an interior solution.
} 
In other words in this group there is no preference for the public good provided through the charitable contributions and the weight put on the bequest term may differ from the other group. We show that depending on how the proceeds of the tax are distributed between the two groups, one can have a tax that is supported by the two groups, or by just one. The relative size of $n$ and $m$ and that of $y$ and $w$ will also matter.

Let $A_{2}$ denote the lump-sum transfer received by a member of Group 2, which is given by $A_{2} \equiv T_{2}+\theta$, where $T_{2}=\sigma b_{2}$ represents the proceeds of the bequest tax tax (in Group 2 and in per capita terms), while $\theta$ is a transfer from Group 1. Returning to the logarithmic specification, we have

$U_{2}=\ln [w-(1+\sigma) b+A]+\beta \ln b$.

This gives from the FOC

$b=\frac{\beta}{1+\beta+\sigma}(w+\theta)$

and the indirect utility

$$
\begin{aligned}
V_{2}(\sigma, \theta)= & \ln \left[\frac{1}{1+\beta+\sigma}(w+\theta)(1+\sigma)\right] \\
& +\beta \ln \left[\frac{\beta}{1+\beta+\sigma}(w+\theta)\right]
\end{aligned}
$$

which can be rewritten as

$$
\begin{aligned}
V_{2}(\sigma, \theta)= & (1+\beta) \ln (w+\theta)-(1+\beta) \ln (1+\beta+\sigma) \\
& +\ln (1+\sigma)+(1+\beta) \ln \beta .
\end{aligned}
$$

We have

$V_{2}(0,0)=(1+\beta) \ln w-(1+\beta) \ln (1+\beta)+\ln 1+\beta \ln \beta$,

and

$$
\begin{aligned}
V_{2}(\sigma, 0)= & (1+\beta) \ln w-(1+\beta) \ln (1+\beta+\sigma) \\
& +\ln (1+\sigma)+\beta \ln \beta .
\end{aligned}
$$

Differentiating this expression with respect to the bequest tax rate yields

$$
\frac{\partial V_{2}(\sigma, 0)}{\partial \sigma}=-\frac{1+\beta}{1+\beta+\sigma}+\frac{1}{1+\sigma}<0
$$

as long a $\beta>0$. The sign of this expression does not come as a surprise. Since the member of this group do not care for the public good, a bequest tax is simply a commodity tax (on identical individuals) whose proceeds are distributed in a lumpsum way. Because of the deadweight loss, this tax decreases welfare. Consequently we have $V_{2}(\sigma, 0)<V_{2}(0,0)$. However, as $\theta$ increases (when there is a transfer from the other group), the impact on Group 2's welfare becomes ambiguous and we have $V_{2}(\sigma, \theta) \lessgtr V_{2}(0,0)$.

\section{Both groups}

So far we have considered the two groups separately. We now consider the entire economy and examine if the level of the transfer $\theta$ can be chosen in a way that the policy increases the welfare of both groups. From Section 2 we have an expression for $\Delta$ the utility gain of each member of Group 1 . Given that $\Delta$ is in utility terms, it should be divided by $n$ to convert it into monetary units (to obtain the compensating variation). ${ }^{6}$ Consequently,

$\theta=n \Delta / n m=\Delta / m$
Table 1

Level of $D$ as a function of $\beta$ and $m$.

\begin{tabular}{lllrrrr}
\hline$m$ & 1 & 5 & 10 & \multicolumn{1}{l}{50} & \multicolumn{1}{l}{100} & 1000 \\
\hline$\beta$ & & & & & & \\
0.01 & 2.047 & 0.84 & 0.504 & 0.113 & 0.515 & -0.007 \\
0.1 & 2.108 & 0.798 & 0.427 & 0.002 & -0.065 & -0.129 \\
0.5 & 2.445 & 0.658 & 0.153 & -0.427 & -0.519 & -0.606 \\
0.9 & 2.86 & 0.598 & -0.042 & -0.777 & -0.893 & -1.004 \\
\hline
\end{tabular}

is the maximum monetary transfer individuals of Group 2 can receive (while ensuring that Group 1 is not worse off than without the policy). The question we are left with is whether or not this transfer $\theta$ along with $\sigma=n-1$ may lead to an increase in the welfare of Group 2.

There will be a welfare improvement if

$$
\begin{aligned}
D & =V_{2}(\sigma, \theta)-V_{2}(0,0) \\
& =\left[V_{2}(\sigma, \theta)-V_{2}(\sigma, 0)\right]-\left[V_{2}(0,0)-V_{2}(\sigma, 0)\right]>0 .
\end{aligned}
$$

The second term in brackets is positive and corresponds to the deadweight loss of the tax. The first term in brackets is positive and increases with $\theta$. It follows that there exists a value of $\theta(\sigma), \hat{\theta}$ such that $D=0$. The question is then to know whether the level of $\theta$ defined by (4) and (3) is sufficiently large to pass this test. To tackle this question, we resort to a numerical example with logarithmic utility and different values for both $\beta$ and $m$. Table 1 reports the implied values of $D .^{7}$ It confirms that there exist values of these two parameters that are compatible with a positive value of $D$. Not surprisingly this occurs when $\beta$ and $m$ are not too large. It thus appears that estate taxation can be supported by both the contributors and the non contributors when it generates a sufficiently significant surplus to the first by fostering contributions to charitable causes. The condition is that this surplus be large enough to compensate Group 2 for the deadweight loss of the tax. When this condition is met there exists room for a potential Pareto improvement. Quite clearly, to achieve a Pareto improvement, the transfer then must be effectively implemented.

\section{Conclusion}

This paper has provided a simple illustrative model that can account for the fact that very rich people often support bequest taxes, while middle class or poor individuals oppose it. The bequest tax may improve the welfare of the rich because it stimulates contributions to a charity (a public good) which is provided through voluntary donations. Middle class individuals, on the other hand, do not care about the charity and loose from the estate tax even when its proceeds are refunded in a lump sum way (because of the deadweight loss). Furthermore we show that as system of inter-group transfers may or may not be sufficient to overcome the opposition of the middle class individuals. Not surprisingly, such transfers can effectively be designed (and a Pareto improvement achieved) when the utility weight of bequests within Group 2 as well as the relative size of the group are not too large.

Our model is admittedly highly stylized and is only remotely related to reality. However, it is intended to illustrate in a simple way one of the factors that affects political support for bequest taxation (or the lack of such a support). We do not claim that it is the only factor nor for that matter necessarily the most significant one. Still it offers a simple explanation for seemingly paradoxical stylized fact. Concern for charities is not the only reason why some

\footnotetext{
6 Recall that the utility function specified by (1) is linear in the public good $G$. Consequently an individual's marginal utility of income is constant and equal to $n$.
} 
wealthy people are in favor of taxation of bequests. Other motives are sometimes invoked like a feeling of gratefulness for a society which has rewarded them so much or the conviction that leaving too much undeserved money to their children can be harmful. ${ }^{8}$ But these considerations are outside the scope of economics.

\section{References}

Andreoni, J., 1988. Privately provided public goods in a large economy: The limits of altruism. Journal of Public Economics 35, 57-73.
Andreoni, J., 2006. Philanthropy. In: Kolm, S.Ch., Mercier Ythier, J. (Eds.), Handbook of Giving, Reciprocity and Altruism, vol. 1. Elsevier North Holland, Amsterdam, The Netherlands.

Bergstrom, T., Blume, L., Varian, H., 1986. On the private provision of public goods. Journal of Public Economics 29, 25-49.

Cremer, H., Pestieau, P., 2011. Taxing wealth and wealth transfers. A survey. In: Albi, E., Martinez-Vazquez, J. (Eds.), The Elgar Guide to Tax Systems. Edward Elgar Publishing, Cheltenham, UK.

Prabhakar, R., 2010. Debating the death tax: the politics of inheritance tax in the UK LSE, London (unpublished).

United for a Fair Economy (2011), New estate tax bill taxes the 1\% to benefit the 99\%, http://faireconomy.org/enews/new_estate_tax_bill_taxes_the_1_to_ benefit_the_99.

\footnotetext{
8 In that respect, one may note that as opposed to the dynastic wealthy (such as Rockefeller), the new wealthy such as Bill gates tend to be more vocal in their support for estate taxation.
} 